\title{
A new approach to determine the chloride threshold initiating corrosion: Preliminary results
}

\author{
Chantal Chalhoub*, Raoul François, and Myriam Carcassés \\ LMDC, Université de Toulouse, INSA, UPS, Toulouse, France
}

\begin{abstract}
The initiation of corrosion by chlorides is traditionally based on the existence of a threshold that would lead to corrosion. Almost all existing approaches considered implicitly that corrosion induced by chlorides is uniform and take not into account the intrinsic localized character of corrosion in reinforced concrete structures. This work aims to implement a new test protocol that takes explicitly into account the localized nature of chlorides-induced corrosion by inducing physical separation between anode and cathode thus permitting to measure the corrosion current. The anodic part allows to test different levels of chlorides and the cathodic part to highlight the ohmic (limiting ionic current by low porosity) and cathodic (restricting access to oxygen due to saturation of porosity, low porosity, dioxygen consumption by additions) control of corrosion. The chloride threshold is set on the basis of a threshold corrosion current that is considered acceptable with respect to the structure's life. The first results provide a preliminary idea of the variation of corrosion rate in function of chlorides content. This method also highlights the influence of surface condition of the steel-concrete interface on the corrosion current.
\end{abstract}

\section{Introduction}

Chloride induced corrosion in concrete is one of the main causes of degradation of reinforced concrete (RC) structures. This mechanism is traditionally based on the existence of a chloride threshold that would lead to corrosion. However, more than 40 years of research in the field of corrosion in RC have failed to determine a realistic and reliable threshold value [1].

Chloride induced corrosion in reinforced concrete is a macrocell system (also referred to as non-uniform or localized corrosion). This means that anodic and cathodic areas at steel-concrete interface are spatially separated. Nevertheless, almost all existing approaches consider implicitly that corrosion induced by chlorides is a microcell system (also referred to as uniform corrosion) and take not into account the intrinsic localized character of corrosion in concrete.

Traditionally, there are two experimental ways to study the corrosion initiation:

The first method is a potential monitoring where a potential drop would be significant of the initiation of corrosion. Feedback on a large number of structures as well as theoretical considerations indicate that an absolute value of potential is insufficient to characterize the state of corrosion of the reinforcement $[2,3]$, contrary to the interpretation given in the standard ASTM C876-91 [4]. Given the dependence of the potential value on the properties of the embedding concrete, it may be envisaged that a potential monitoring over time is a better indicator of corrosion initiation than a potential value $[2,3]$. This method has been adopted in several studies to detect the initiation of corrosion in the case of reinforcement embedded in concrete [5-10].

Nevertheless, a potential drop does not give any information on the corrosion rate and moreover, the dependence between potential and corrosion current is uncleared. It is also possible that other oxidation-reduction couples than those implementing the corrosion process are responsible for variations in the potential. Garcia et al. [10] monitored the potential of reinforcement bars during the gradual contamination of concrete with chloride ions, in order to detect the potential drop characteristic of the initiation of corrosion. Very negative potential values (between -600 and $-700 \mathrm{mV} / \mathrm{SCE}$ ) were found with formulations with high substitution levels of slag despite the absence of any corrosion. The potential values were constant during the monitoring and no potential drop occurred. The tests in solution and some results on concretes with pozzolanic additives confirmed the participation of sulfides in the corrosion process which could explain the lower potential values obtained.

The second technique is a measure of the linear polarization resistance. This measurement is one of the most widespread methods especially on site that is supposed to provide information on the kinetics of corrosion which allows a more realistic vision of the life of the structure in the presence of corrosion unlike the measurement of corrosion potential. The main advantages of this measure are its speed, its ease of implementation and the low overvoltage required for the realization of the measurement (low disturbance of the system). However, this method is interpreted by the Stern-Geary theory [11], which was established for the case of uniform corrosion [12-14]. The uniform corrosion is by this means

\section{*Corresponding author: Chantal.chalhoub@insa-toulouse.fr}


implicitly assumed in corrosion rate measurements. The main reason why the application of the Stern-Geary [11] equation to localized corrosion is fundamentally incorrect is the fact that the physical separation of anode and cathode makes it impossible to apply the mixed potential theory established by Wagner and Traud [15]. Moreover, several authors reported difficulty in understanding polarization measurements and identified lots of problems related to the application of this technique in the case of macrocell corrosion [16, 17]. In fact, the distribution of the polarizing current in the macrocell system was found to be dependent on the polarization nature (anodic or cathodic) and magnitude. Laurens et al. [18] found that the apparent linear polarization range was much higher in the case of chloride induced macrocell systems than usually assumed. He proved that the polarizing current in a macrocell corrosion system was spread over passive areas in case of cathodic polarization. In the other hand, in case of anodic polarization, the externally applied polarizing current is collected by anodic areas [18]. This result was also established by Elsener showing that the response of a macrocell system is different than the response of uniform corrosion systems [19]. Recently, Angst and Büchler called into question the applicability of the Stern-Geary equation in case of macrocell systems to determine the corrosion rate using linear polarization resistance measurements [20]. They demonstrated that the reason why the application of the Stern-Geary equation to galvanic cells often assumed to yield acceptable results is that two major errors have a compensating effect so that they cancel each other out. However, this agreement depends on specific conditions rather than a fundamental applicability of the method making the existing techniques inaccurate. As mentioned above, the theory on which the linear polarization resistance is based does not correspond to the real conditions of the measurement (especially in the case of a steel in a cementitious material). As a result, this method is not applicable in the case of localized corrosion and it is difficult to obtain quantitative information on the rate of corrosion [21].

Hence, a new test was needed to enable rapid implementation and reliable measurement of localized corrosion. This work aims to implement a new test protocol that takes explicitly into account the localized nature of chlorides-induced corrosion by inducing a physical separation between the anode and cathode thus permitting to measure the galvanic corrosion current flowing between anode and cathode. The anodic part allows to test different levels of chlorides and the cathodic part to highlight the ohmic (limiting ionic current by low porosity) and cathodic (restricting access to oxygen due to the saturation of porosity, low porosity, dioxygen consumption by additions such as slag) control of corrosion. In this paper, the test protocol conditions and test specimens description is detailed. The first results provide a preliminary idea of the variation of the corrosion rate in function of the measured chloride content. The proposed method also highlights the influence of the surface condition of the steel-concrete interface on the corrosion current.

\section{Experimental test protocol}

The experimental program allows to reproduce the process of non-uniform corrosion by inducing a physical separation between the anode and cathode thus permitting to measure the galvanic corrosion current. This is done by preparing mortar samples without chlorides called cathodes to represent cathodic sites and other test specimens called anodes immersed in saline solutions to represent anodic sites. This two-piece installation will permit to identify separately the different components of corrosion (anodic, cathodic and ohmic) and to quantify the exchange (the corrosion current) between the anodic and cathodic zones, which was impossible in classical tests protocol with only one steel bar [9]. In the test context, we will study the variation of corrosion according to several parameters. This study will enable us to understand the "physics" of the localized corrosion phenomenon in the presence of chlorides and to set the factors needed for establishing a reliable experimental test protocol that allows the prediction of the galvanic corrosion current.

\subsection{Description of test specimens}

The use of reinforced mortar specimens instead of reinforced concrete allowed to limit the size of the samples. The water/binder ratio was set at 0.55 and the sand/binder ratio at 2.75 . The cathodic samples are cylindrical $(\$ 110 \times 220 \mathrm{~mm})$ with a cover of $5.2 \mathrm{~cm}$. At the center of each sample is embedded a $160 \mathrm{~mm}$ long Fe500 ribbed steel bar of $6 \mathrm{~mm}$ diameter (Fig. 1). The anodic samples are also cylindrical $(\$ 33 \times 70 \mathrm{~mm})$ embedding at the center of each one a $10 \mathrm{~mm}$ long steel bar of $6 \mathrm{~mm}$ diameter thus presenting a cover of $1.35 \mathrm{~cm}$ (Fig. 2).

In order to ensure a good electrical connection during electrochemical testing, an electrical wire was tin welded to each steel bar. The upper and lower parts of the steel bars were covered with tin leaving only the lateral surface of the steel uncovered.

On site, reinforcement bars are often covered with a layer of mill scale (high temperature phase formed during the cooling of iron) or have a layer of corrosion related to the action of rainwater or formed during their prolonged outdoor exposure. This is why the study of the effect of the surface condition of steel is essential. Consequently, four different types of steel were used to prepare test specimens:

- As received steel "ARS": steel without treatment presenting a non-uniform layer of mill scale like lots of reinforcement bars on site.

- Cleaned Steel "CS": steel cleaned with a chemical cleaning procedure based on the standards of ISO 8407 [22] using an acid solution to remove the mill scale layer.

- Cleaned Steel Pre-oxidized by high Temperature "CSPT": steel cleaned then oxidized with a heat treatment of $72 \mathrm{~h}$ at $400{ }^{\circ} \mathrm{C}$ in order to obtain a homogeneous layer of corrosion products which composition is close to that of the mill scale found in 
the case of as received steel bars which is made up mostly of magnetite with a little hematite.

- Cleaned Steel Pre-oxidized by exposure to Humid environment "CSPH": steel cleaned then oxidized for two weeks in a humid environment with conditions similar to those encountered on site. The layer of corrosion products formed using this method should be less uniform than that formed on "CSPT".

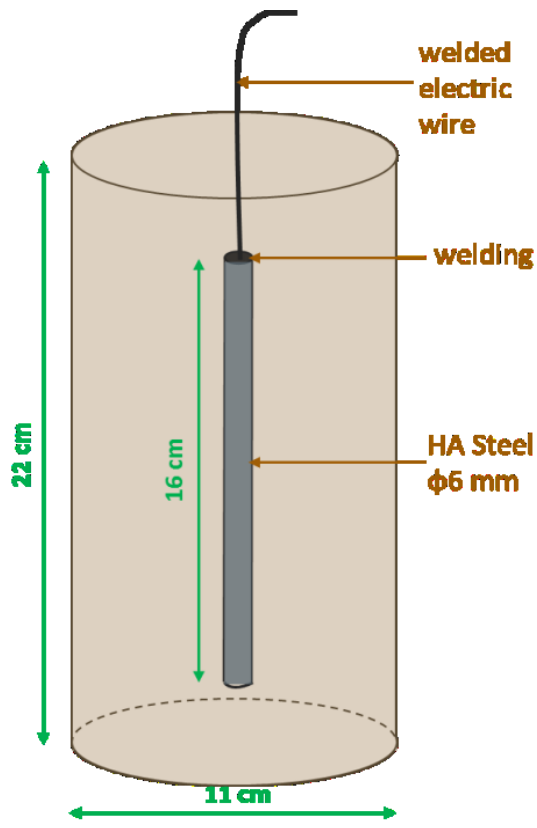

Fig. 1. Cathodic test specimen.

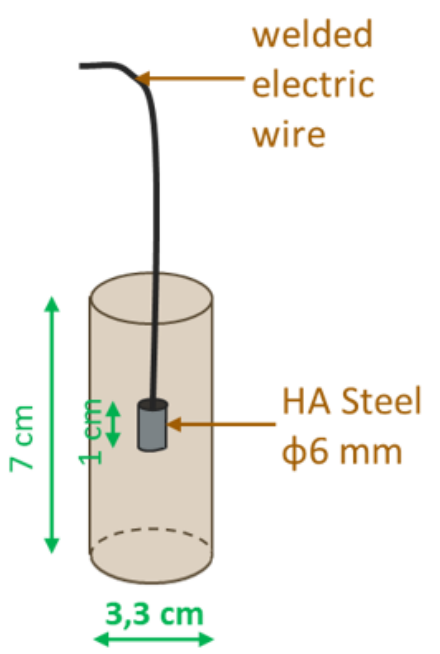

Fig. 2. Anodic test specimen.

\subsection{Test conditions}

\subsubsection{Drying of anodic specimens}

At the end of the wet cure (28 days), the anodic specimens were dried in a humidity controlled oven of $25 \%$ at a temperature of $45{ }^{\circ} \mathrm{C}$ until constant mass. The objective of drying is to avoid the diffusion phase of chlorides hence accelerating their penetration into samples. The temperature was limited to $45{ }^{\circ} \mathrm{C}$ to prevent the destabilization of hydrates and cracking (removal of differential desiccation between the heart and the surface of the test piece) which may affect the penetration of chlorides through the concrete. The drying time required to stabilize the mass of the anodes was between 20 and 30 days of drying.

\subsubsection{Immersion of anodic specimens in saline solutions}

The introduction of chlorides was realized after the end of drying by imbibition of anodes in $1 \mathrm{~L}$ of $\mathrm{NaCl}$ solutions with controlled chlorides contents. Thus, chlorides are present at the beginning of the test and in a priori known quantity which will also be measured retrospectively after the destruction of the samples to visualize the steel/mortar interface. The electrical wires that were welded to the bars were protected by silicone to prevent penetration of chlorides through them. The samples were fully immersed for 48 hours in saline solutions with different sodium chloride $(\mathrm{NaCl})$ concentration: 12.25, 22.75, 70, 140 and $280 \mathrm{~g} / \mathrm{L}$. These contents are expected to lead to a total chloride content in $\%$ of the mass of cement, respectively to: $0.175 \%, 0.325 \%, 1 \%, 2 \%, 4 \%$. The cathode specimens remain intact and can be reused several times.

\subsection{Electrochemical tests: Anode-cathode coupling and measurement of galvanic corrosion current}

After two days of immersion in the saline solution, each anodic specimen was placed with the corresponding cathode in a sodium hydroxide solution $(\mathrm{NaOH})$ with a part of the test pieces that remained above the level of the solution as shown in Fig.3. All tests are done at a temperature of $20^{\circ} \mathrm{C}$ in a temperature controlled room.

The anode and cathode samples separated by a distance of $30 \mathrm{~cm}$ were connected by a potentiostat controlled by EC-LabR) software using the ZRA (Zero Resistance Ammeter) electrochemical technique. This application consists in applying zero volts between the connected electrodes and then measuring the galvanic coupling current between them. The microstructure differences between both electrodes result in the fact that one of them behaves anodically and the other one behaves cathodically. The sodium hydroxide solution provided an alkaline environment with a $\mathrm{PH}$ of 13.5 similar to the $\mathrm{PH}$ measured in the interstitial solution of concrete. The solution allowed the flow of the ionic current consequently ensuring the galvanic coupling. The measurement of the current flowing between the two samples was maintained for 7 days to be in a steady state (stabilization of the corrosion current).

It is important to emphasize that if the anode is left alone with its chlorides, a non-uniform corrosion will take place on a single bar with impossibility to measure the corrosion current. Furthermore, when the anode and cathode are connected, there are still non-uniform corrosion currents in the anode but it is assumed that they 
are negligible especially if the size of the cathode is significantly larger than that of the anode.

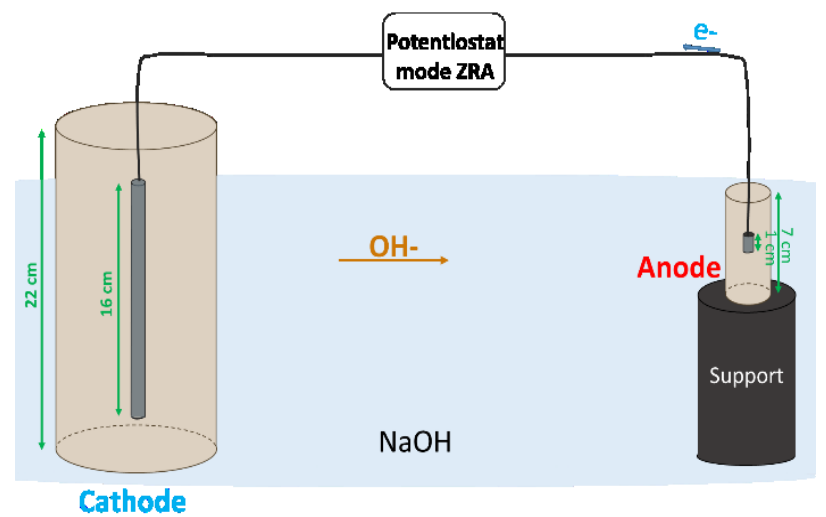

Fig. 3. Cathode-anode coupling and direct measurement of the galvanic corrosion current.

This two-specimen assembly allows quantifying the galvanic current between anodic and cathodic zones, which was not possible in the single-specimen setups found in the literature [9]. This galvanic corrosion current will be studied according to the concentration of the saline solution and the type of steel used.

The potential of anode and cathode was measured before connecting the two samples and a measurement of the potential was realized after disconnecting both samples at the end of the corrosion test. The criterion for the duration of the depolarisition process was set at duration of 60 minutes from which both potential were stabilized. In general, the potentials measured with respect to a reference electrode placed on the surface of the concrete facing do not represent the potential in contact with the reinforcement. These potentials depend on the position of the reference electrode because of the ohmic drop due to the resistivity of the embedding concrete. In this test protocol, all of the anode specimens and cathode samples are correspondingly identical and axi-symmetrical having a constant cover thickness which is the same regardless of the position of the reference electrode. Therefore, the potential measurements can be comparable.

\subsection{Determination of total chlorides content by mass of cement}

Total chloride content is measured at the end of the corrosion test in the anode to confirm that the imbibition process have led to the expected chloride content at the vicinity of the rebar.

The determination of chlorides in mortar powder requires a minimum sample weight of $4 \mathrm{~g}$. Thus, mortar was taken at the level of the steel bar with a thickness of $5 \mathrm{~mm}$ as shown in Fig.4. The determination of total chloride ions (free and bound) is carried out according to the standard NF-EN-14629 [23].

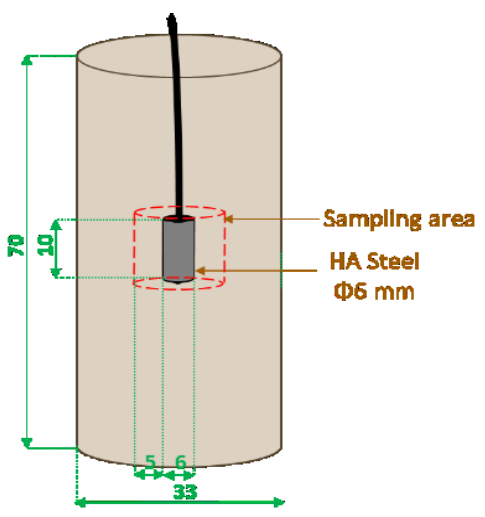

Fig. 4. Sampling area for the determination of chlorides content (dimensions in $\mathrm{mm}$ ).

\section{Results and discussion}

\subsection{Experimental galvanic corrosion current}

\subsubsection{Influence of chlorides content and steel surface condition on galvanic corrosion current}

Fig.5. presents the apparent galvanic average current densities measured on the tested specimens with four types of steel for different levels of total chlorides expressed in \%/weight of binder. Each point on the graph represents the result of two tests. The average current is calculated on the 7 days of the duration of testing. This current is divided by the surface of the anode, that's why it is called apparent density.

Concerning the cleaned pre-oxidized steel in a humid environment samples, an increase of the current density with the chloride level was observed. As for cleaned steel pre-oxidized with high temperature, the current densities obtained with those specimens are close to those of the pre-oxidized steel in a humid chamber. The same behavior was observed in case of as received steel.

The scattering outcomes obtained with bars with mill scale layer is not something new. In fact, Ghods and al. have shown that the presence of micro cracks in the mill scale layer makes the crevices at the steel-mill scale interface accessible by the porous solution and could lead to cavernous corrosion. According to the authors this mechanism could partly explain the dispersion of $\mathrm{C}_{\text {crit }}$ values for steel bars with presence of mill scale [24]. The similarity of behavior between these 3 types of steel may be attributed to the similarity in the composition of the mill scale layer found on the as received steel and the one formed on cleaned pre-oxidized steel. The non-uniformity of these layers may justify the presence of some irregular current densities obtained. However, it may be possible to have less dispersion with the cleaned steel pre-oxidized in high temperature since the oxide layer formed using this treatment should be more homogeneous than the mill scale layer. These assumptions are still preliminary and need further developments. 


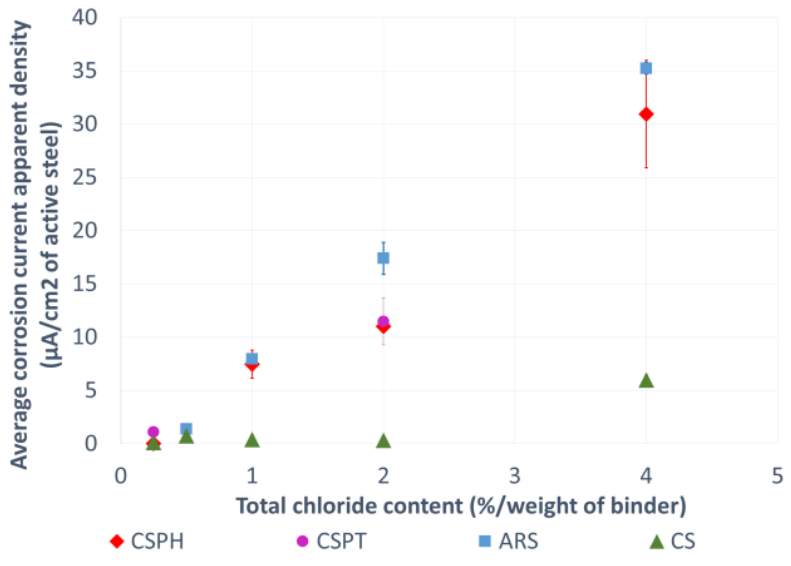

Fig. 5. Average corrosion current density versus total chloride content in the sampling area

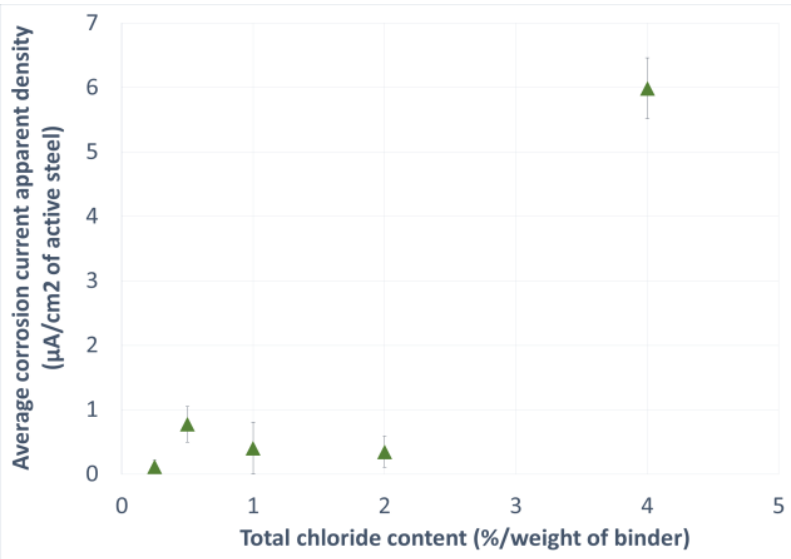

Fig.6. Average corrosion current density versus total chloride content in the case of cleaned steel (a scaled-up presentation of the same data in Fig. 5)

The corrosion densities obtained with cleaned steel specimens (Fig. 6) are low compared to those obtained with samples formed with other steel types. However, for very high chloride levels of $4 \%$, the current densities reached 6.5 and $5.5 \mu \mathrm{A} / \mathrm{cm}^{2}$. The apparent current density monitoring measured in the case of both test pieces shows that the current densities were negligible during the first days or hours and then increased. This phenomenon may be attributed to a certain diffusion time needed for the chloride ions to pass through the passivation layer formed on the cleaned steel.

The results show that the passive layer formed on steel in the absence of mill scale or pre-oxidized process (case of cleaned steel) are less porous to chloride ingress than those formed in the presence of mill scale (case of as received steel) and those formed on cleaned pre-oxidized steel. This result is consistent with the work of E. Mahallati and al. who studied the influence of the presence of mill scale by cyclic polarization tests. The authors noticed that the passivity current was higher in the case of steel bars with mill scale layer. The formation, growth and maintenance of the passive layer depends on the accessibility of the metal cations by oxygen and hydroxide ions. The mill scale layer could constitute a barrier disrupting the formation of the passive layer [25]. Horne and al. also showed that the amount of portlandite near the reinforcement is nearly $30 \%$ higher in the case of polished steel than steel where the mill scale layer has been preserved. This would have the effect of improving the buffering capacity of the concrete at the steel-concrete interface [26].

An overall vision of the results clearly shows that the increase in chloride levels leads to an increase in corrosion currents. However, there may be a maximum amount of chlorides "useful" for a given anode surface, i.e; the corrosion current would reach a plateau for a higher chloride content than those tested in this study. An increase of the ratio cathode/anode could also have an information on this point, it will be part of further research.

\section{Conclusions}

In this paper was described a new test protocol based on the phenomenology of localized corrosion. This twopiece installation first permit to quantify the exchanged corrosion current between anodic (active) and cathodic (passive) zones, which was impossible in test realized on a single bar sample. The test also allows to study the influence of different parameters on the corrosion process which makes it possible to quantify later on the corrosion anodic, cathodic and ohmic components.

The first preliminary results highlight the influence of chlorides content and steel surface on corrosion rate. It was deduced that an increase in chloride levels leads to an increase of the corrosion current densities. According to this increase in corrosion current density, an acceptable level of chloride would be defined based on a duration of the propagation phase. It will be a part of further research.

This experimental test would be completed with a numerical approach based on a finite element model using the local Ohm's law and the differentiated "macroscopic" steel-concrete interface conditions on the active and passive sites. These conditions would be the ButlerVolmer equations deduced from experimental steady state polarization curves realized separately on anodic and cathodic samples. This approach makes it possible to validate the prediction of the corrosion currents from the experimental quantification of the Butler-Volmer conditions for a given binder. It is also envisaged to take into account the transport of oxygen to the cathode zones by the modification of the "cathodic" Butler-Volmer condition.

A second approach which could be adopted in the modeling part is an analytical approach based on a model allowing a prediction of the maximum local corrosion rate. This model could be a function of all the different parameters influencing the corrosion such as factors related to anode (like the level of free chlorides and the nature of the passivation layer formed on steel), elements related to cathode (like the availability of oxygen at cathode), and parameters associated to geometry of the corrosion system which is the cathode-anode ratio and finally environment (for e.g. variables related to ionic conduction, resistivity, steel-mortar interface defects and temperature). 


\section{References}

1. U. Angst, B. Elsener, C.K. Larsen, Ø. Vennesland, Critical chloride content in reinforced concrete - a review, Cem. Concr. Res. 39, 1122-1138 (2009)

2. B. Elsener, C. Andrade, J. Gulikers, R. Polder,M. Raupach, Half-cell potential measurements Potential mapping on reinforced concrete structures, Mater. Struct. 36, 461-471 (2003)

3. R. François, G. Arliguie, D. Bardy, Electrode potential measurements of concrete reinforcement for corrosion evaluation, Cement and Concrete Research, Vol. 24, n³, 401-412 (1994)

4. ASTM C876-09, "Standard Test Method for Corrosion Potentials of Uncoated Reinforcing Steel in Concrete", ASTM International, West Conshohocken, PA (2009) www.astm.org."

5. P.Sandberg, Chloride initiated reinforcement corrosion in marine concrete, $\mathrm{PhD}$ thesis, Lund Institute of Technology, Division of Building Materials, Sweden (1998)

6. U.M. Angst, B. Elsener, C.K. Larsen, U.M.Øystein Vennesland, chloride induced reinforcement corrosion: Electrochemical monitoring of initiation stage and chloride threshold values, Corrosion Science 53, 14511464 (2011)

7. N.R. Jarrah, S. Baghabra, O. Al-Amoudi, M. Maslehuddin, A. Oluwatoyin Ashiru, Abdulaziz Ibrahim Al-Mana, Electrochemical behavior of steel in plain and blended cement concretes in sulfates and/or chloride environments, Construction and Building Materials 9, 97-103 (1995)

8. V. Bouteiller, C. Cremona, V. Baroghel-Bouny, A. Maloula, Corrosion initiation of reinforced concretes based on Portland or GGBS cements: Chloride contents and electrochemical characterizations versus time, Cement and Concrete Research 42, 1456-1467 (2012)

9. Report of RILEM TC235 CTC in preparation

10. Vincent Garcia, Raoul François, Myriam Carcasses, Philippe Gégout, Potential measurement to determine the chloride threshold concentration that initiates corrosion of reinforcing steel bar in slag concretes, Materials \& Structures, Volume 47, Issue 9, 1483-1499 (2014)

11. Stern, M., Geary, A.L. Electrochemical Polarization I. A Theoretical Analysis of the Shape of Polarization Curves, J.Electrochem. Soc. 104, 56-63 (1957)

12. M. Stern, A.L. Geary, Electrochemical polarization, J. Electrochem. Soc. 104, 56-63 (1957)

13. C. Andrade, C. Alonso, J. Gulikers, R. Polder, R. Cigna, Ø. Vennesland, M. Salta, A. Raharinaivo, B. Elsener, Test methods for on-site corrosion rate measurement of steel reinforcement in concrete by means of the polarization resistance method, Mater. Struct. 37, 623-643 (2004)

14. A. Clement, S. Laurens, G. Arliguie, F. Deby, Numerical study of the linear polarization resistance technique applied to reinforced concrete for corrosion assessment, Eur. J. Environ. Civ. Eng. 16, 491-504 (2012)

15. C. Wagner, W. E. Traud, Z. Elektrochem. Angew. Phys. Chem. 44, 397 (1938)

16. A.A. Sagüés, S.C. Kranc, on the determination of polarization diagrams of reinforcing steel in concrete, Corrosion 48, 624-633 (1992)

17. J. Gulikers, Numerical simulation of corrosion rate determination by linear polarization, in: C. Andrade, C. Alonso, J. Fullea, J. Polimon, J. Rodriguez (Eds.),PRO 18: Measurement and Interpretation of the on-site corrosion rate, volume, Proceedings of the International Workshop MESINA, 145-156 (2015)

18. S. Laurens, P. Hénocq, N. Rouleau, F. Deby, E. Samson, J.Marchand, B. Bissonnette, Steadystate polarization response of chloride-induced macrocell corrosion systems in steel reinforced concrete - numerical and experimental investigations, Cement and Concrete Research 79, 272-290 (2016)

19. B. Elsener, Macrocell corrosion of steel in concrete - implications for corrosion monitoring, Cem. Concr. Compos. 24, 65-72 (2002)

20. U. Angst, M. Büchler, on the applicability of the Stern-Geary relationship to determine instantaneous corrosion rates in macro-cell corrosion, Mater. Corros. (2014)

21. Raoul Francois, Stéphane Laurens, Fabrice Deby, Corrosion and its Consequences for Reinforced Concrete Structures, 1st Edition, eBook ISBN: 9780081023457, Hardcover ISBN: 9781785482342, Imprint: ISTE Press Elsevier, 232, (2018)

22. INTERNATIONAL STANDARD ISO 8407 , Corrosion of metals and alloys-Removal of corrosion products from corrosion test specimens, Table A.1, C.3.2a, (2009)

23. NF EN 14629, Afnor (2007)

24. P. Ghods, O.B. Isgor, G.A. McRae, J. Li, G.P. $\mathrm{Gu}$ Microscopic investigation of mill scale and its proposed effect on the variability of chlorideinduced depassivation of carbon steel rebar Corrosion Science 53, 946-954 (2011)

25. E. Mahallati, M. Saremi, An assessment on the mill scale effects on the electrochemical characteristics of steel bars in concrete under DC-polarizationCement and Concrete Research 36, 1324-1329 (2006)

26. A.T. Horne, I.G. Richardson, R.M.D. Brydson, Quantitative analysis of the microstructure of interfaces in steel reinforced concrete, Cement and Concrete Research 37, 1613-1623 (2007) 